The Free Internet Journal

for Organic Chemistry
Paper

Arkivoc 2020, part 0-0

to be inserted by editorial office

\title{
Unique cyclolignan's architecture obtained via acid catalyzed cyclization/intramolecular Friedel-Crafts tandem reaction
}

\author{
Krzysztof K. Krawczyk, Kamil Lisiecki, and Zbigniew Czarnocki*
}

Faculty of Chemistry, University of Warsaw, Pasteura 1, 02-093 Warsaw, Poland

Email:czarnoz@chem.uw.edu.pl

\section{Dedicated to Professor Jan Bergman on the occasion of his $80^{\text {th }}$ birthday}

Received mm-dd-yyyy

Accepted mm-dd-yyyy

Published on line mm-dd-yyyy

Dates to be inserted by editorial office

\section{Abstract}

We examine the cyclization of chiral bis-benzylidenesuccinate 6 (precursor to podophyllotoxin-related cyclolignans) in different conditions. Under acid catalysis, a new type of cyclolignan was obtained via cyclization/intramolecular Friedel-Crafts tandem reaction. The structure of the product was confirmed by spectroscopic data and X-ray diffraction. Also, a plausible mechanism of this transformation was proposed.
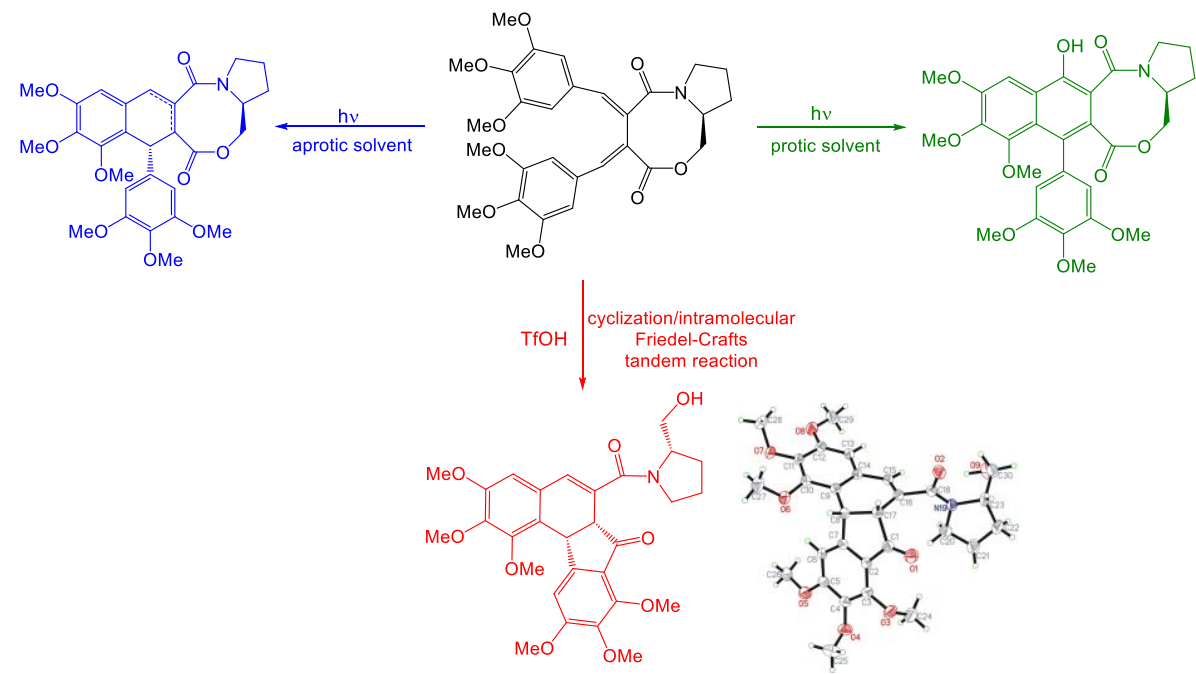

Keywords: Cyclolignans, cyclization, L-prolinol, tandem reaction 


\section{Introduction}

Cyclolignans are a large group of natural compounds with a broad spectrum of biological activities. ${ }^{1}$ The best known representative of this class of compounds is podophyllotoxin (PPT, 1), and its semisynthetic derivatives - etoposide (2) and teniposide (3) (Figure 1), mostly due to their antiproliferative and antiviral activity. ${ }^{2-5}$

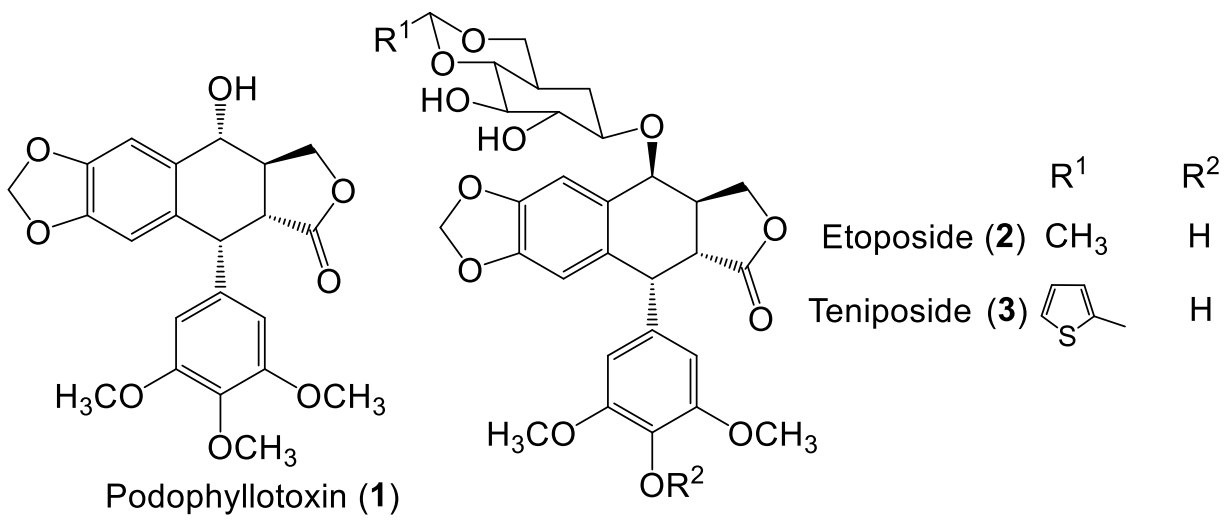

Figure 1. Chemical structures of podophyllotoxin (1), etoposide (2) and teniposide (3).

The growing demand for effective anticancer drugs and the depletion of natural sources of cyclolignans ${ }^{6}$ has caused interest in developing synthetic pathways leading to this type of compounds. ${ }^{7-9}$ Our research group is interested in the stereoselective synthesis of cyclolignans, achieved by photocyclization of chiral bis-benzylidenesuccinates. ${ }^{10}$ We found that L-prolinol is an excellent chiral auxiliary ${ }^{11}$ and used for the formal synthesis of $\mathrm{PPT}^{12}$ and the total synthesis of (+)-epigalcatin. ${ }^{13}$ We also studied the regioselectivity in the photocyclization of cyclolignan precursors ${ }^{14}$ and we used the bis-benzylidenesuccinyl platform as a photolabile protecting group for secondary amines. ${ }^{15}$

Although the photocyclization of chiral bis-benzylidenesuccinates is relatively better studied, it is also possible to obtain cyclolignans via acid catalyzed cyclization, as shown in Charlton's total synthesis of (+)-lyoniresinol dimethyl ether, in which (-)-ephedrine was used as a chiral auxiliary and triflic acid (TfOH) as the catalyst. ${ }^{16}$ Herein, we report a case in which the acid catalyzed cyclization of a chiral bis-benzylidenesuccinate was followed by an intramolecular Friedel-Crafts cyclization, leading to a novel type of cyclolignan. The results are compared with these obtained for the photocyclization of 6 in protic and aprotic solvents.

\section{Results and Discussion}

\section{Synthesis of axially chiral bis-benzylidenesuccinate}

The synthetic pathway starts with the opening of fulgide 4 (prepared according to previously reported procedure ${ }^{15}$ ) with L-prolinol leading to succinamic acid $\mathbf{5}$. An atroposelective macrolactonization using BOP (benzotriazol-1-yloxytris(dimethylamino)phosphonium hexafluorophosphate ; Castro's reagent) as a coupling agent gave product 6 with 93\% yield (Scheme 1). Only one rotamer was obtained, which was confirmed by NMR analysis. In our previous studies ${ }^{12,14}$ we have shown that the use of L-prolinol as a chiral auxiliary provides the $P$-isomer of the macrocyclic compounds of type 6 (bis-benzylidenesuccinate cyclic amide-ester), which additionally had the cis configuration at C-1 and C-2 chiral centers and the same absolute configuration as in $\mathbf{1}$. This is a clear advantage of L-prolinol over (-)-ephedrine, which induces the $M$-configuration ${ }^{16}$ of the 
bis-benzylidenesuccinate cyclic amide-ester and, after cyclization, leads to a trans configuration at C-1 and C-2, and the absolute configuration at $\mathrm{C}-1$ opposite to that found in $\mathbf{1 .}$
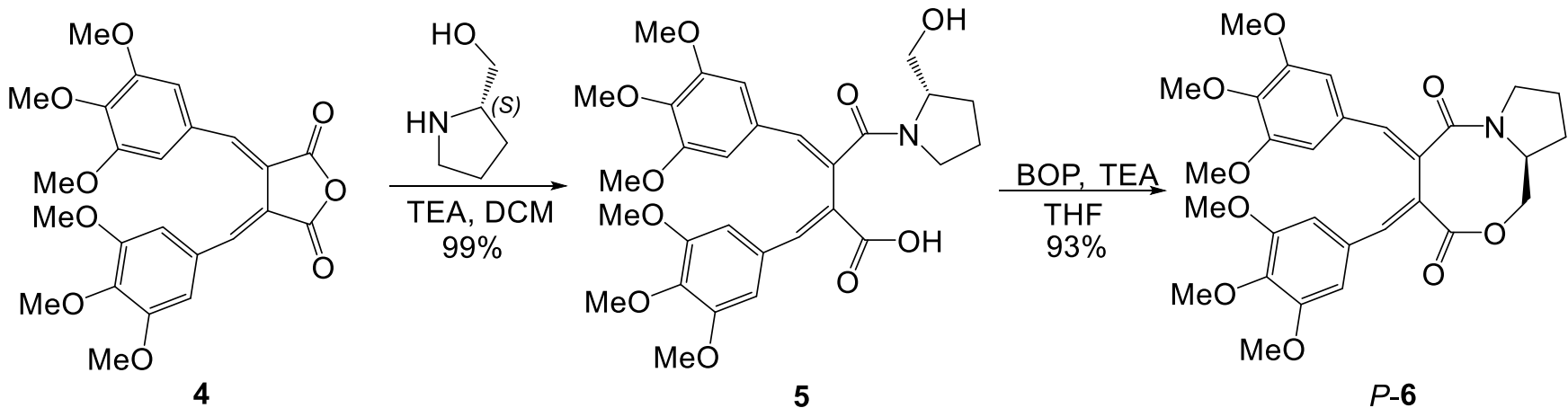

Scheme 1. The synthesis of cyclic amidester 6.

\section{Photocyclization}

With product 6 in hand, we started to study the cyclization of this compound in different conditions. We began with a photocyclization using a medium-pressure mercury lamp ( $\lambda_{\max } \approx 365 \mathrm{~nm}$ ). In $\mathrm{CHCl}_{3}$ and protic solvents $(\mathrm{MeOH}$ and $\mathrm{AcOH})$ a strong photochromism was observed during the irradiation, but the reaction mixture gradually bleached and became fluorescent under UV-light. The isolated product was subjected to spectral analysis. Mass spectrometry showed that the molecular weight exceeded by 14 units the mass of 6 . Additionally, ${ }^{1} \mathrm{H}$ NMR spectrum showed singlet at $10.24 \mathrm{ppm}$ characteristic for phenol $-\mathrm{OH}$ group. These observations led us to conclusion that an aromatization of the naphthalene ring occurred, along with the incorporation of an oxygen atom at C-4 (Scheme 2).

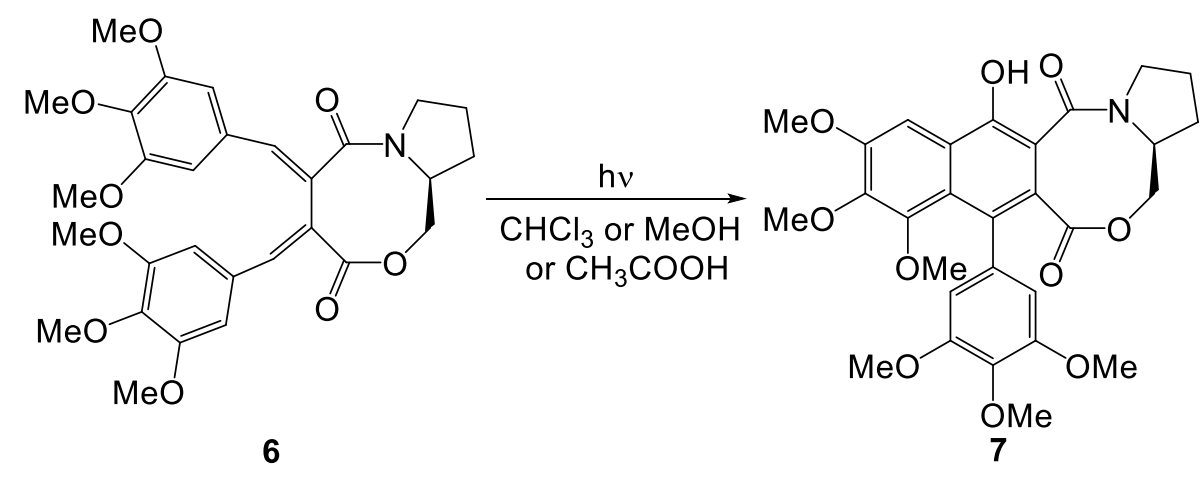

Scheme 2. Photocyclization of 6 in protic solvents.

In aprotic solvent (toluene) we observed a color change from slightly yellow to red during the irradiation, which indicates formation of an intermediate product. The color did not disappear even after long irradiation and no product was isolated. We decided to add an acidic additive to protonate the intermediate. After addition of $p$-toluenesulfonic acid ( $p$ - TsOH, catalytic amount) discoloration has occurred instantaneously and an intense blue fluorescence appeared (Figure 2.). 


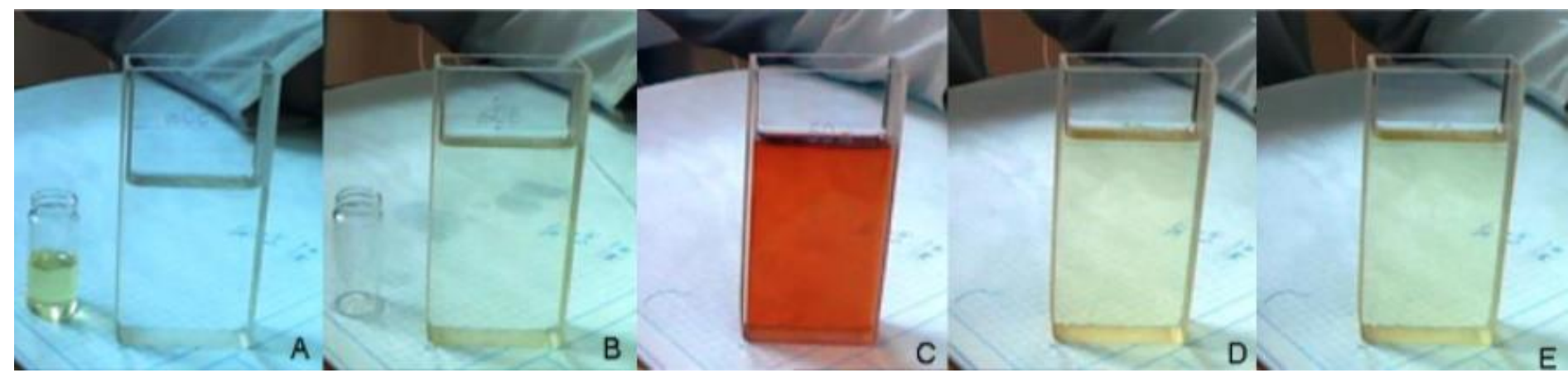

Figure 2. Photographs of reaction mixture during irradiation of 6 in toluene. A - pure toluene in cuvette and solution of $\mathbf{6}$ in toluene in a vial; B - solutions after mixing in cuvette; $\mathrm{C}$ - solution during the irradiation without acidic additive; $\mathrm{C}$ - solution during irradiation immediately after addition of acidic additive; D solution during irradiation few minutes after addition of acidic additive.

After column chromatography we isolated compounds $\mathbf{8}$ and $\mathbf{9}$ as a mixture. Their preparative separation by column chromatography was not possible. We have noticed that aromatization of compounds 8 and $\mathbf{9}$ to compound 10 (confirmed by NMR and MS analyzes) occurred during column chromatography and in solution (air oxidation) (Scheme 3).
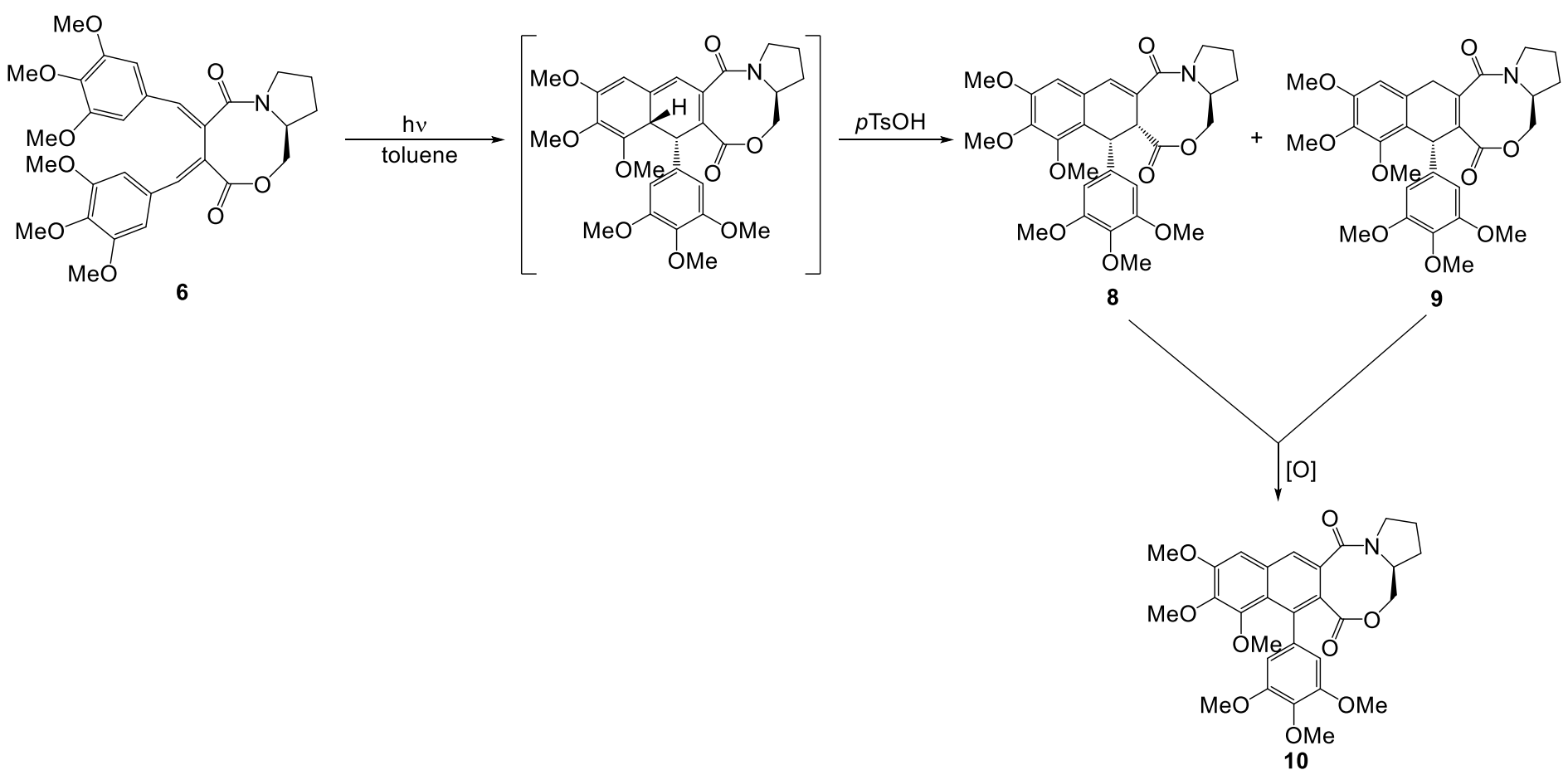

Scheme 3. Photocyclization of 6 in aprotic solvent.

\section{Acid catalyzed cyclization}

Based on Charlton's results, ${ }^{16}$ we performed an analogous experiment, in which a solution of 6 was treated with $\mathrm{TfOH}$. The reaction mixture immediately became coloured upon the addition of TfOH, but after purification we obtained a single product with $83 \%$ yield. ${ }^{1} \mathrm{H}$ NMR analysis revealed only 3 aromatic protons and we thus assumed the creation of an additional ring, most likely as a result of an intermolecular FriedelCrafts reaction, which occurred after cyclization (Scheme 4). From the HMBC, HSQC and COSY spectra (see 
Supporting Information) we concluded that the proton at C-1 position is a doublet at $4.13 \mathrm{ppm}$ and $\mathrm{J}=8.4 \mathrm{~Hz}$ and proton at C-2 position is a doublet at $4.87 \mathrm{ppm}$ and $J=8.4 \mathrm{~Hz}$. In the ROESY spectrum (see Suporting Information) we observed an interaction between these protons which indicates a cis configuration.<smiles>COc1cc(/C=C2/C(=O)OC[C@@H]3CCCN3C2=O)cc(OC)c1OC</smiles>

6<smiles>COc1cc2c(c(OC)c1OC)C(=O)[C@]1(C)c3cc(OC)c(OC)c(OC)c3[C@@]2(O)c2c(OC)c(OC)c(OC)cc21</smiles>

11

Scheme 4. Acid catalyzed cyclization of 6.

Good quality crystals were obtained by slow evaporation of the EtOAc/Et ${ }_{2} \mathrm{O}$ mixture and single crystal X-ray diffraction was performed (Figure 3.), which confirmed the structure of $\mathbf{1 1}$, which represents a novel, unique class of cyclolignans with potential biological activity.

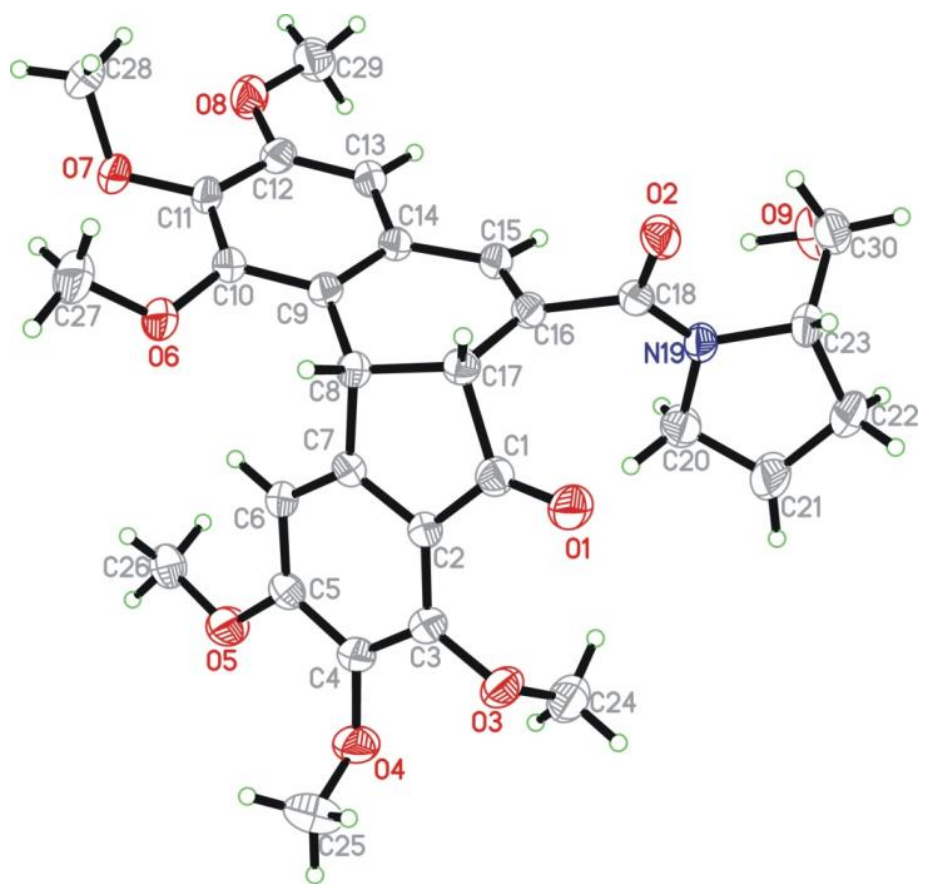

Figure 3. The ORTEP view of the molecule. The non-hydrogen atoms are shown as $30 \%$ probability ellipsoids.

A reasonable mechanism for this transofmation is presented in Scheme 5. It starts with the protonation of the ester carbonyl group. After migration of the double bond, the carbocation at benzylic position is formed, which is prone to cyclization to form the central dihydronaphtalene motif. The dihydronaphtalene is deprotonated at the $\mathrm{C} 9$ position and protonated from the less hindered side at C2, to form the partially aromatic 1,2-dihydronaphtalene ring. This leads to formation of carbocation at the C12 position that allowed a subsequent intramolecular Friedel-Crafts reaction. Then, the 8-membered ring is opened and in the last step oxygen atom is protonated leading to compound $\mathbf{1 1 .}$ 

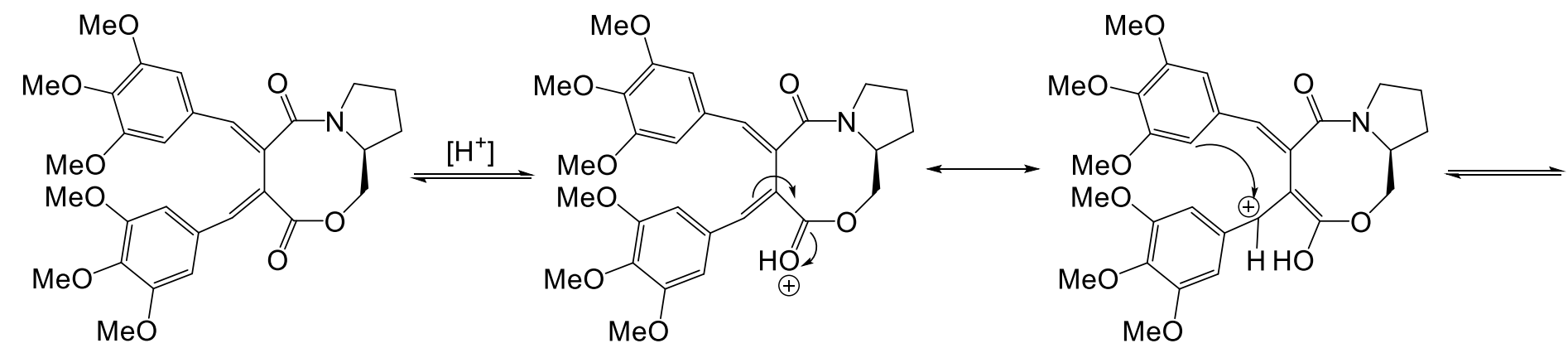

6

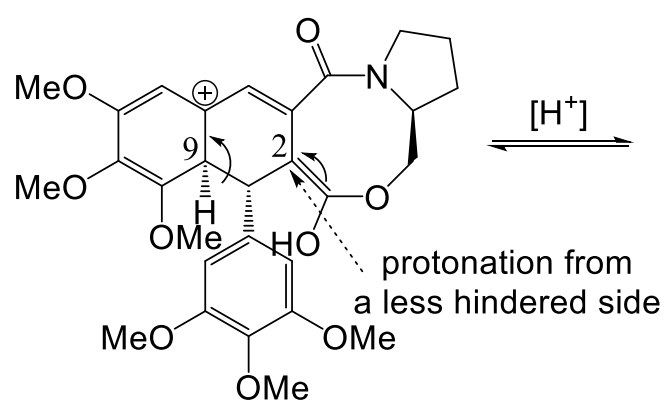

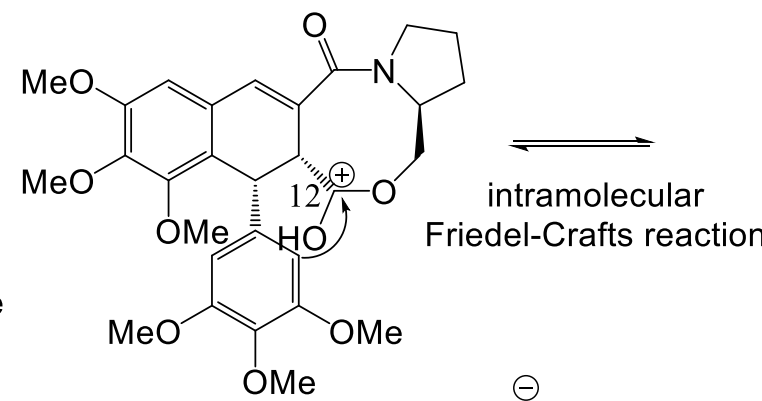

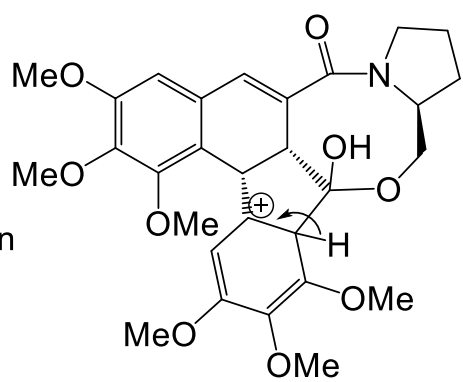<smiles>COc1cc2c(c(OC)c1OC)[C@@H]1c3cc(OC)c(OC)c(OC)c3[C@@]3(O)OC[C@H]4CCCN4C(=O)C(=C2)[C@H]3C1(O)O</smiles><smiles>C=CC</smiles><smiles>COc1cc2c(c(OC)c1OC)C(=O)[C@H]1C(C(=O)N3CCC[C@H]3C[O-])=Cc3cc(OC)c(OC)c(OC)c3[C@H]21</smiles><smiles>COc1cc2c(c(OC)c1OC)C(=O)[C@H]1C(C(=O)N3CCC[C@H]3CO)=Cc3cc(OC)c(OC)c(OC)c3[C@H]21</smiles>

Scheme 5. The mechanism of acid catalyzed transformation of 6 into 11.

Johnson et al. obtained a similar polycyclic architecture using Rh catalyzed intramolecular hydroacylation of an appropriate trisubstituted alkene. ${ }^{17}$ However, compared to our results the previous method requires a heavy metal catalyst, leads to the racemic product and has low yield (43\%).

\section{Conclusions}

We have studied cyclization of chiral bis-benzylidenesuccinate $\mathbf{6}$ in different conditions. Acid catalyzed cyclization led us to product with additional ring resulting from intramolecular Friedel-Craft reaction. We have confirmed its structure by X-ray diffraction and proposed a plausible reaction mechanism. The resulting compound belongs to a still unexplored class of cyclolignans with potential biological activity. In comparison to previous synthesis of similar polycyclic compounds, our approach avoids the use of heavy metal catalysts and leads to the product in its single enantiomeric form. We believe that the reaction is driven both by the high protonating power of the superacid $\mathrm{TfOH}$ and the high electron density at the trimethoxy-substituted aryl rings. Further experiments with differently substituted bis-benzylidenesuccinates are currently underway.

\section{Experimental Section}


General. The reagents and solvents were commercially available and were used without further purification. Thin layer chromatography (TLC) analyses were performed on Merck Kieslgel 60 F-254 plates and visualization was done under UV light. Evaporation of solvents was performed at reduced pressure, using a Büchi rotary evaporator. Melting points were determined on an Electrothermal, Model IA 9200 apparatus and are uncorrected. ${ }^{1} \mathrm{H}$ and ${ }^{13} \mathrm{C}$ NMR spectra were recorded on a Bruker AVANCE 500 spectrometer. Chemical shifts were reported in ppm from tetramethylsilane with the solvent resonance as the internal standard in $\mathrm{CDCl}_{3}$ solution. The following abbreviations are used: $\mathrm{m}$-multiplet, s-singlet, d-doublet, t-triplet, q-quartet, br-broad. High-resolution mass (ESI-TOF MS) spectra were recorded on a Micromass LCT spectrometer. (3E,4E)-3,4-Bis(3,4,5-trimethoxybenzylidene)dihydrofuran-2,5-dione (4) was synthesized as reported previously. ${ }^{10}$

\section{(2E,3E)-3-((S)-2-(Hydroxymethyl)pyrrolidine-1-carbonyl)-2-(3,4,5-trimethoxybenzylidene)-4-(3,4,5-}

trimethoxyphenyl)but-3-enoic acid (5). Fulgide 4 (1.00 g, $2.19 \mathrm{mmol}, 1.0$ equiv.) was dissolved in $\mathrm{CH}_{2} \mathrm{Cl}_{2}(15$ $\mathrm{mL}$ ) and L-prolinol (234 $\mathrm{LL}, 2.40 \mathrm{mmol}, 1.05$ equiv.) dissolved in $\mathrm{CH}_{2} \mathrm{Cl}_{2}(1 \mathrm{~mL})$ was added. The mixture was stirred at room temperature for $2 \mathrm{~h}$. The mixture was concentrated under reduced pressure and the residue was dissolved EtOAc $(20 \mathrm{~mL})$. The resulting solution was washed once with a $10 \%$ aqueous solution of citric acid $(20 \mathrm{~mL})$ and once with brine $(20 \mathrm{~mL})$. The organic layer was separated and dried over anhydrous $\mathrm{Na}_{2} \mathrm{SO}_{4}$. The drying agent was filtered off and the solvent was evaporated, yielding $1.21 \mathrm{~g}(2.17 \mathrm{mmol}, 99 \%)$ of a thick oil. The identity of the product was confirmed by mass spectrometry. HRMS (ESI-TOF) $\mathrm{m} / \mathrm{z}$ : calcd for $\mathrm{C}_{29} \mathrm{H}_{35} \mathrm{NO}_{10} \mathrm{Na}[\mathrm{M}+\mathrm{Na}]^{+}, 580.2159$; found, 580.2163.

$(S, 4 E, 5 E)-4,5$-bis-(3,4,5-trimethoxybenzylidene)tetrahydro-1H-pyrrolo[2,1-c][1,4]oxazocine-3,6(8H,9H)-dione (6). Compound 5 (500 mg, $0.90 \mathrm{mmol}, 1.0$ equiv.) was dissolved in anhydrous THF under argon atmosphere. Then, BOP (416 mg, $0.94 \mathrm{mmol}, 1.05$ equiv.) was added in one portion and the mixture was cooled to $-45^{\circ} \mathrm{C}$. Triethylamine ( $138 \mu \mathrm{L}, 0.99 \mathrm{mmol}, 1.1$ equiv.) dissolved in anhydrous THF $(1 \mathrm{~mL})$ was added and the mixture was allowed to reach room temperature and then stirred at $35^{\circ} \mathrm{C}$. After $1.5 \mathrm{~h}$ of stirring the mixture was concentrated under reduced pressure and the residue was dissolved in AcOEt $(15 \mathrm{~mL})$. The resulting solution was washed twice with $10 \%$ aqueous citric acid solution $(10 \mathrm{~mL})$, then 4 times with $5 \%$ aqueous $\mathrm{NaHCO}_{3}$ solution $(10 \mathrm{~mL})$, once with water $(10 \mathrm{~mL})$ and once with brine $(10 \mathrm{~mL})$. The organic layer was separated and dried over anhydrous $\mathrm{Na}_{2} \mathrm{SO}_{4}$. After filtration and evaporation, the resulting yellow oil was purified by column chromatography (silica gel) using the $\mathrm{Et}_{2} \mathrm{O} / \mathrm{EtOAc}$ (7:3 vol./vol.) mixture as an eluent. Compound 6 (452 mg, $0.84 \mathrm{mmol}, 93 \%)$ was obtained in the form of yellowish amorphous solid. $[\alpha]_{\mathrm{D}}^{20}+485\left(c 1.00, \mathrm{CHCl}_{3}\right) .{ }^{1} \mathrm{H} \mathrm{NMR}$ $(500 \mathrm{MHz}) \delta: 7.58(\mathrm{~s}, 1 \mathrm{H}), 7.50(\mathrm{~s}, 1 \mathrm{H}), 7.04(\mathrm{~s}, 2 \mathrm{H}), 6.88(\mathrm{~s}, 2 \mathrm{H}), 4.67\left(\mathrm{dd}, J_{1} 13.5 \mathrm{~Hz}, J_{2} 4.5 \mathrm{~Hz}, 1 \mathrm{H}\right), 4.35(\mathrm{~d}, J$ $13.5 \mathrm{~Hz}, 1 \mathrm{H}), 4.09(\mathrm{~m}, 1 \mathrm{H}), 3.90(\mathrm{~s}, 6 \mathrm{H}), 3.87(\mathrm{~s}, 3 \mathrm{H}), 3.86(\mathrm{~s}, 6 \mathrm{H}), 3.84(\mathrm{~s}, 3 \mathrm{H}), 3.58-3.51(\mathrm{~m}, 1 \mathrm{H}), 3.54-3.48(\mathrm{~m}$, $1 \mathrm{H}), 2.33(\mathrm{br} \mathrm{q}, J \approx 6 \mathrm{~Hz}, 1 \mathrm{H}), 1.96-1.91(\mathrm{brq}, J \approx 6 \mathrm{~Hz}, 1 \mathrm{H}), 1.76-1.58(\mathrm{~m}, 2 \mathrm{H}) .{ }^{13} \mathrm{C} \mathrm{NMR}(125 \mathrm{MHz}) \delta: 168.6$, 167.3, 153.5, 153.4, 145.5, 141.6, 140.6, 140.0, 129.4, 128.9, 127.6, 125.0, 108.7, 107.9, 73.7, 61.1, 61.1, 60.0, 56.6, 56.4, 48.4, 34.8, 22.7. HRMS (ESI-TOF) $\mathrm{m} / z$ calcd for $\mathrm{C}_{29} \mathrm{H}_{33} \mathrm{NO}_{9} \mathrm{Na}[\mathrm{M}+\mathrm{Na}]^{+}, 562.2053$; found, 562.2047.

\section{(S)-12-Hydroxy-8,9,10-trimethoxy-7-(3,4,5-trimethoxyphenyl)-2,3,3a,4-tetrahydro-1H-naphtho[2,3-}

f]pyrrolo[2,1-c][1,4]oxazocine-6,13-dione (7). In a $50 \mathrm{~mL}$ quartz cuvette, $50 \mathrm{mg}$ (0.093 mmol) of compound 6 was dissolved in $50 \mathrm{~mL}$ of $\mathrm{MeOH}$ and the solution was flushed with dry argon for $1 \mathrm{~h}$. The reaction mixture was irradiated using a medium pressure mercury lamp. During irradiation, the solution was vigorously flushed with dry argon, which guaranteed constant mixing and deaeration of the solution. The color of the reaction mixture changed within the first $20 \mathrm{~s}$ of irradiation from colorless to yellow with a strong blue fluorescence. After 40 min of irradiation the solution was transferred into a round bottom flask and the solvent was removed under vacuum. The resulting yellow oil was purified on a silica gel column using Et ${ }_{2} \mathrm{O} /$ EtOAc (gradient, from $50 \%$ to $100 \%$ of EtOAc) mixture as an eluent. Product 7 (23.5 mg, $0.044 \mathrm{mmol}, 47 \%)$ was obtained in the form of a 
thick oil. ${ }^{1} \mathrm{H}$ NMR (500 MHz) $\delta: 10.24$ (br s, $\left.1 \mathrm{H},\{\mathrm{ArOH}\}\right), 7.56(\mathrm{~s}, 1 \mathrm{H}), 6.47(\mathrm{~s}, 2 \mathrm{H}), 4.68$ (dd, $J_{1} 13.0 \mathrm{~Hz}, J_{2} 6.5 \mathrm{~Hz}$, $1 \mathrm{H}), 4.06\left(\mathrm{dd}, J_{1} 13.0 \mathrm{~Hz}, J_{2} 3.5 \mathrm{~Hz}, 1 \mathrm{H}\right), 4.04(\mathrm{~s}, 3 \mathrm{H}), 3.90(\mathrm{~s}, 3 \mathrm{H}), 3.89(\mathrm{~s}, 3 \mathrm{H}), 3.84(\mathrm{~s}, 3 \mathrm{H}), 3.79(\mathrm{~s}, 3 \mathrm{H}), 3.77(\mathrm{~d}, J$ $\approx 3 \mathrm{~Hz}, 1 \mathrm{H}), 3.58-3.53(\mathrm{~m}, J \approx 6 \mathrm{~Hz}, 1 \mathrm{H}), 3.36(\mathrm{~s}, 3 \mathrm{H}), 2.14-2.06(\mathrm{~m}, 2 \mathrm{H}), 2.03-1.98(\mathrm{~m}, 2 \mathrm{H}), 1.94-1.89(\mathrm{~m}$,

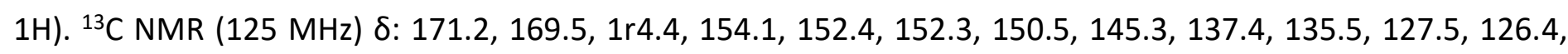
$125.4,123.1,108.5,108.2,105.7,98.8,68.1,61.3,61.2,61.1,59.3,56.5,56.3,56.3,48.1,33.2,22.2$. HRMS (ESI-TOF) $\mathrm{m} / \mathrm{z}$ calcd for $\mathrm{C}_{29} \mathrm{H}_{31} \mathrm{NO}_{10} \mathrm{Na}[\mathrm{M}+\mathrm{Na}]^{+}$: 576.1846; found, 576.1839.

Irradation of 6 in aprotic solvent. In a $50 \mathrm{~mL}$ quartz cuvette, $50 \mathrm{mg}(0.093 \mathrm{mmol})$ of compound 6 was dissolved in $50 \mathrm{~mL}$ of toluene and the solution was flushed with dry argon for $1 \mathrm{~h}$. The reaction mixture was irradiated using a medium pressure mercury lamp. During irradiation, the solution was vigorously flushed with dry argon, which guaranteed constant mixing and deaeration of the solution. The color of the reaction mixture changed within the first $20 \mathrm{~s}$ of irradiation from colorless to dark red. Then, a solution of $p$-toluenesulfonic acid (one crystal) in toluene $(2 \mathrm{~mL})$ was added and the solution became pale yellow, with a strong blue fluorescence under UV light. After $40 \mathrm{~min}$ of irradiation the solution was transferred into a round bottom flask and the solvent was removed under vacuum. The resulting yellow oil was purified on a silica gel column using $\mathrm{Et}_{2} \mathrm{O} /$ EtOAc (gradient, from $50 \%$ to $100 \%$ of EtOAc) and then a mixture of $1 \%$ of $\mathrm{MeOH}$ in $\mathrm{CHCl}_{3}$ as an eluent. Compounds 8 and 9 (in total $35 \mathrm{mg}, 0.065 \mathrm{mmol}, 70 \%$ ) were obtained as a mixture and compound 10 (7 mg, $0.013 \mathrm{mmol}, 14 \%)$ as pure product. Mixture of (3aS,6aR,7R)-8,9,10-trimethoxy-7-(3,4,5-trimethoxyphenyl)2,3,3a,4,6a,7-hexahydro-1H-naphtho[2,3-f]pyrrolo[2,1-c][1,4]oxazocine-6,13-dione (8) and (3aS,7R)-8,9,10trimethoxy-7-(3,4,5-trimethoxyphenyl)-2,3,3a,4-tetrahydro-1H-naphtho[2,3-f]pyrrolo[2,1-c][1,4]oxazocine6,13(7H,12H)-dione (9). ${ }^{1} \mathrm{H}$ NMR (500 MHz) $\delta: 6.58(\mathrm{~s}, 1 \mathrm{H}, 8), 6.55(\mathrm{~s}, 1 \mathrm{H}, 9), 6.54(\mathrm{~d}, J 3.0 \mathrm{~Hz}, 1 \mathrm{H}, 8), 6.31(\mathrm{~s}$, $2 \mathrm{H}, 9), 6.25$ (br s, 2H, 8), 5.19 (dd, J1 $\left.4.2 \mathrm{~Hz}, J_{2} 3.3 \mathrm{~Hz}, 1 \mathrm{H}, 9\right), 4.97$ (d, J $\left.8.9 \mathrm{~Hz}, 1 \mathrm{H}, 8\right), 4.44$ (dd, J1 $8.9 \mathrm{~Hz}, J_{2} 3.1$ $\mathrm{Hz}, 1 \mathrm{H}, 8), 4.24$ (dd, J1 $\left.14.0 \mathrm{~Hz}, J_{2} 3.8 \mathrm{~Hz}, 1 \mathrm{H}, 8\right), 4.09$ (d, J $\left.3.1 \mathrm{~Hz}, 1 \mathrm{H}, 8\right), 4.06(\mathrm{~m}, 2 \mathrm{H}, 9), 3.89$ (s, 3H, 8), 3.88 (s, $3 \mathrm{H}, 9), 3.84(\mathrm{~s}, 3 \mathrm{H}, 9), 3.81(\mathrm{~s}, 3 \mathrm{H}, 8), 3.80(\mathrm{~s}, 3 \mathrm{H}, 9), 3.77(\mathrm{~s}, 3 \mathrm{H}, 8), 3.75(\mathrm{~s}, 6 \mathrm{H}, 9) 3.71(\mathrm{~s}, 6 \mathrm{H}, 8), 3.65(\mathrm{~d}, J 6.6$ $\mathrm{Hz}, 2 \mathrm{H}, 8), 3.53(\mathrm{~s}, 3 \mathrm{H}, 8), 3.47(\mathrm{~s}, 3 \mathrm{H}, 9), 3.18(\mathrm{~d}, \mathrm{~J} 14.6 \mathrm{~Hz}, 1 \mathrm{H}, 8), 2.13-2.07(\mathrm{~m}, 2 \mathrm{H}, 8), 2.04-2.01(\mathrm{~m}, 2 \mathrm{H}, 8)$, $1.94-1.82(\mathrm{~m}, 4 \mathrm{H}, 9)$. HRMS (ESI-TOF) $\mathrm{m} / z$ calcd for $\mathrm{C}_{29} \mathrm{H}_{33} \mathrm{NO}_{9} \mathrm{Na}[\mathrm{M}+\mathrm{Na}]^{+}: 562.2053$; found, 562.2011. (S)8,9,10-trimethoxy-7-(3,4,5-trimethoxyphenyl)-2,3,3a,4-tetrahydro-1H-naphtho[2,3-f]pyrrolo[2,1-

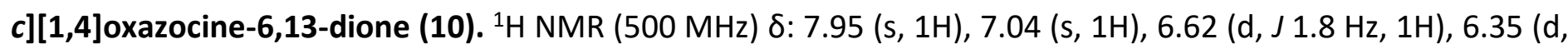
J $1.8 \mathrm{~Hz}, 1 \mathrm{H}), 4.35\left(\mathrm{dd}, J_{1} 6.1 \mathrm{~Hz}, J_{2} 12.5 \mathrm{~Hz}, 1 \mathrm{H}\right), 4.00(\mathrm{~s}, 3 \mathrm{H}), 3.90(\mathrm{~s}, 3 \mathrm{H}), 3.89(\mathrm{~s}, 3 \mathrm{H}), 3.84(\mathrm{~s}, 3 \mathrm{H}), 3.80(\mathrm{~s}, 3 \mathrm{H})$, $3.73-3.70(\mathrm{~m}, 1 \mathrm{H}), 3.61(\mathrm{~m}, 1 \mathrm{H}), 3.38(\mathrm{~s}, 3 \mathrm{H}), 2.15-2.09(\mathrm{~m}, 1 \mathrm{H}), 2.05-1.96(\mathrm{~m}, 3 \mathrm{H}), 1.92-1.85(\mathrm{~m}, 1 \mathrm{H}), 1.33$ $-1.28(\mathrm{~m}, 1 \mathrm{H})$. HRMS (ESI-TOF) $\mathrm{m} / z$ calcd for $\mathrm{C}_{29} \mathrm{H}_{31} \mathrm{NO}_{9} \mathrm{Na}[\mathrm{M}+\mathrm{Na}]^{+}: 560.1897$; found, 560.1932 .

(6aR,11bR)-6-((S)-2-(Hydroxymethyl)pyrrolidine-1-carbonyl)-1,2,3,8,9,10-hexamethoxy-6aH-

benzo[c]fluoren-7(11bH)-one (11). In a round bottom flask, $100 \mathrm{mg}(0.19 \mathrm{mmol}, 1.0$ equiv.) of compound 6 was dissolved in anhydrous DCM ( $5 \mathrm{~mL})$. Then, $17 \mu \mathrm{L}(29 \mathrm{mg}, 0.19 \mathrm{mmol}, 1.0$ equiv.) of TfOH was added and the solution immediately changed color from yellow to dark red and then black. Reaction mixture was refluxed for $8 \mathrm{~h}$. After this time, the mixture was allowed to cool down to ambient temperature, poured into a beaker containing $5 \%$ sodium bicarbonate solution. Phases were separated and aqueous layer was extracted twice $\mathrm{DCM}(2 \times 10 \mathrm{~mL})$. The combined organic layers were dried over anhydrous $\mathrm{Na}_{2} \mathrm{SO}_{4}$, filtered and concentrated. The crude product was purified by column chromatography (silica gel) using Et ${ }_{2} \mathrm{O} / \mathrm{EtOAc}$ (1:1 vol./vol.) mixture as an eluent. Compound 11 (83 mg, $0.15 \mathrm{mmol}, 83 \%)$ was obtained and crystallized by slow evaporation of the EtOAc/Et ${ }_{2} \mathrm{O}$ mixture. Mp. $176-178^{\circ} \mathrm{C}$. $[\alpha]_{\mathrm{D}}{ }^{20}+637$ (c 1.00, $\left.\mathrm{CHCl}_{3}\right) .{ }^{1} \mathrm{H} \mathrm{NMR}(600 \mathrm{MHz}) \delta: 6.78(\mathrm{~s}, 1 \mathrm{H}), 6.52(\mathrm{~s}$, $1 \mathrm{H}), 6.48(\mathrm{~s}, 1 \mathrm{H}), 4.87(\mathrm{~d}, J 8.4 \mathrm{~Hz}, 1 \mathrm{H}), 4.33(\mathrm{br} \mathrm{q}, J 4.5 \mathrm{~Hz}, 1 \mathrm{H}), 4.13(\mathrm{~d}, J 8.4 \mathrm{~Hz}, 1 \mathrm{H}), 4.07(\mathrm{br} d, J 10.0 \mathrm{~Hz}, 1 \mathrm{H})$, $4.01(\mathrm{~s}, 3 \mathrm{H}), 3.98(\mathrm{~s}, 3 \mathrm{H}), 3.95(\mathrm{~s}, 3 \mathrm{H}), 3.84(\mathrm{~s}, 3 \mathrm{H}), 3.81(\mathrm{~s}, 3 \mathrm{H}), 3.80(\mathrm{~s}, 3 \mathrm{H}), 3.53\left(\mathrm{dd}, J_{1} 12.0 \mathrm{~Hz}, J_{2} 5.0 \mathrm{~Hz}, 1 \mathrm{H}\right)$, $3.47(\mathrm{~m}, 2 \mathrm{H}), 3.37-3.30$ (br s, disappears when $\mathrm{D}_{2} \mathrm{O}$ is added, $\left.1 \mathrm{H}\right), 2.15-2.11(\mathrm{~m}, 1 \mathrm{H}), 1.90-1.87(\mathrm{~m}, 1 \mathrm{H})$, $1.85-1.81(\mathrm{~m}, 1 \mathrm{H}), 1.77-1.72(\mathrm{~m}, 1 \mathrm{H}) .{ }^{13} \mathrm{C} N M R(150 \mathrm{MHz}) \delta: 200.1,170.1,160.2,154.6,152.9,151.9,151.2$, 
142.8, 141.1, 131.9, 126.8, 126.4, 119.7, 119.5, 107.9, 103.9, 64.6, 62.1, 61.4, 61.2, 60.9, 60.3, 56.1, 56.0, 51.0, $50.1,36.3,27.7,25.1$. HRMS (ESI-TOF) $\mathrm{m} / z$ calcd for $\mathrm{C}_{29} \mathrm{H}_{33} \mathrm{NO}_{9} \mathrm{Na}[\mathrm{M}+\mathrm{Na}]^{+}: 562.2053$; found, 562.2032. The detailed structural parameters have been deposited with the Cambridge Crystallographic Data Centre under the number CCDC 1977939.

\section{Supplementary Material}

Supplementary material related to this article can be found, in the online version, at doi:

\section{References}

1. Liu, Y.-Q.; Yang, L.; Tian, X. Curr. Bioact. Compd. 2007, 3, 37.

https://doi.org/10.2174/157340707780126499

2. King, M. L.; Sullivan, M. M. Science 1946, 104, 244.

https://doi.org/10.1126/science.104.2698.244

3. Sullivan, B. J.; Wechsler, H. J. Science 1947, 105, 433.

https://doi.org/10.1126/science.105.2730.433

4. Gordaliza, M.; Castro, M. A.; Miguel del Corral, J. M.; San Feliciano, A. Curr. Pharm. Design. 2000, 6, 1811.

https://doi.org/10.1126/science.105.2730.433

5. Schacter, L. Semin. Oncol. 1996, 6(suppl 13), 1.

6. Sun, J.-S.; Liu, H.; Guo, X.-H.; Liao, J.-X. Org. Biomol. Chem. 2016, 14, 1188.

https://doi.org/10.1039/C5OB02188J

7. Yu, X.; Che, Z.; Xu, H. Chem. Eur. J. 2017, 23, 4467.

https://doi.org/10.1002/chem.201602472

8. Pan, J.-Y.; Chen, S.-L.; Yang, M.-H.; Wu, J.; Sinkkonen, J.; Zou, K. Nat. Prod. Rep. 2009, 26, 1251. https://doi.org/10.1039/b910940d

9. Sellars, J. D.; Steel, P. G. Eur. J. Org. Chem. 2007, 3815.

https://doi.org/10.1002/ejoc.200700097

10. Lisiecki, K.; Czarnocki, Z. Org. Prep. Proced. Int. 2018, 50, 527.

https://doi.org/10.1080/00304948.2018.1537239

11. Krawczyk, K. K.; Madej, D.; Maurin, J. K.; Czarnocki, Z. Tetrahedron: Asymmetry 2011, 22, 1103. https://doi.org/10.1016/j.tetasy.2011.06.007

12. Lisiecki, K.; Krawczyk, K. K.; Roszkowski, P.; Maurin, J. K.; Czarnocki, Z. Org. Biomol. Chem. 2016, 14, 460.

https://doi.org/10.1039/C5OB01844G

13. Lisiecki, K.; Czarnocki, Z. Org. Lett. 2018, 20, 605.

https://doi.org/10.1021/acs.orglett.7b03974

14. Lisiecki, K.; Roszkowski, P.; Krawczyk, K. K.; Maurin, J. K.; Czarnocki, Z. J. Photochem. Photobiol. A Chem. 2018, 364, 297.

https://doi.org/10.1016/j.jphotochem.2018.06.023 
15. Lisiecki, K.; Krawczyk, K. K.; Roszkowski, P.; Maurin, J. K.; Budzianowski, A.; Czarnocki, Z. Tetrahedron 2017, 73, 6316.

https://doi.org/10.1016/j.tet.2017.09.021

16. Assoumatine, T.; Datta, P. K.; Hooper, T. S.; Yvon, B. L.; Charlton, J. L. J. Org. Chem. 2004, 69, 4140. https://doi.org/10.1021/jo0497454

17. Johnson, K. F.; Schneider, E. A.; Schumacher, B. P.; Ellern, A.; Scanlon, J. D.; Stanley, L. M. Chem. Eur. J. 2016, 22, 15619.

https://doi.org/10.1002/chem.201603880

This paper is an open access article distributed under the terms of the Creative Commons Attribution (CC BY) license (http://creativecommons.org/licenses/by/4.0/) 